\title{
Necrobiosis Lipoidica: Atypical Presentation in a Diabetic Girl
}

\author{
Meshal M. Alhameedy \\ Department of Dermatology, King Fahad Specialist Hospital, Buraydah, Saudi Arabia
}

\author{
Keywords \\ Necrobiosis lipoidica · Granuloma · Diabetes · Pediatric
}

\section{Abstract}

Necrobiosis lipoidica $(\mathrm{NL})$ is a chronic granulomatous idiopathic disorder. It usually presents as yellow-brown, atrophic, telangiectatic plaques with an elevated violaceous rim, typically in the pretibial region of both extremities with and without ulceration [1, 2]. There are few reported cases of childhood-onset NL in atypical locations. We report a case of type 1 diabetic 13 -year-old girl who developed yellow atrophic plaque with telangiectasia on the extensor aspect of her upper arm.

\section{Introduction}

Necrobiosis lipoidica (NL) is a chronic granulomatous idiopathic disorder, first described by Oppenheim in 1929 and renamed as necrobiosis lipoidica diabeticorum by Urbach in 1932 . It typically affects females $20-30$ years old with earlier onset in diabetic patients. It affects $0.3-1.2 \%$ of diabetic patients. Thyroid dysfunction is also found in $13 \%$ of NL patients. It usually presents as yellow-brown, atrophic, telangiectatic plaques with an elevated violaceous rim, typically in the pretibial region of both extremities with and without ulceration [1-3].

\section{Case Report/Case Presentation}

A 13-year-old type 1 diabetic girl presented to our dermatology clinic with a complaint of solitary asymptomatic atrophic yellow-brown plaque with prominent telangiectasia measuring $6 \times 4 \mathrm{~cm}$ over the extensor aspect of her upper left arm enlarging over the past 
Fig. 1. Solitary atrophic yellow-brown plaque with prominent telangiectasia measuring $6 \times 4 \mathrm{~cm}$ over the extensor aspect of the upper left arm.

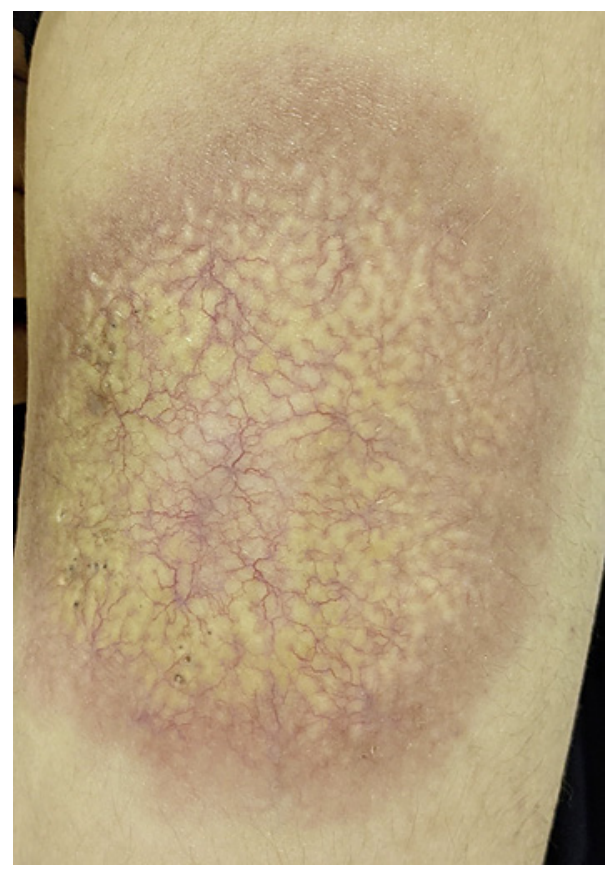

Fig. 2. Dermoscopic examination revealed prominent branching arborizing blood vessels in a yellow-white background.

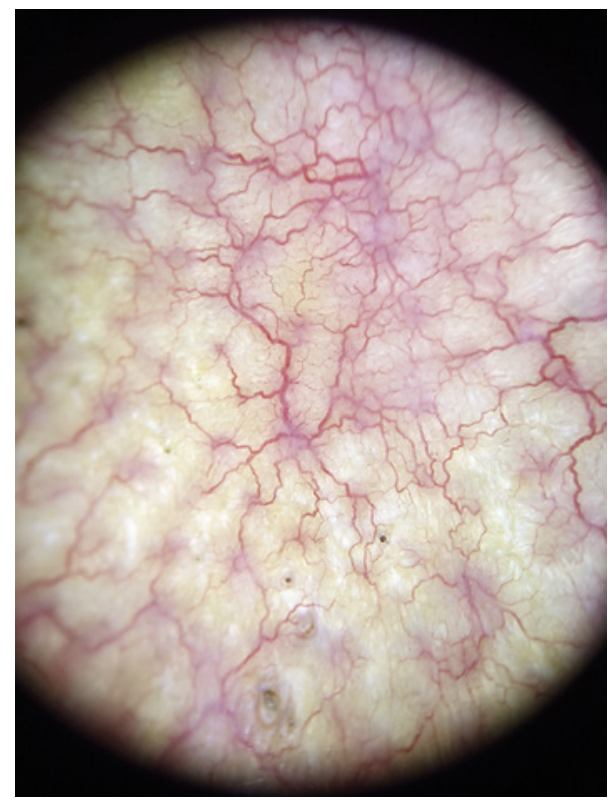

3 years (shown in Fig. 1). A dermoscopic examination revealed prominent branching arborizing blood vessels in a yellow-white background (shown in Fig. 2). A full-body skin examination including the scalp, oral, and genital mucosa, teeth, hair, palms, and soles showed that these areas were not affected. The physical examination included her developmental milestones, which were unremarkable. She was diagnosed with type 1 diabetes when she was 2 years old and has had insulin injections since then. She had no systemic symptoms or complaints at the time of presentation. Histopathological examination showed full-thickness epithelioid granulomatous infiltrate alternating with necrobiotic degenerated collagen associated 
Fig. 3. Histopathological examination showed full-thickness epithelioid granulomatous infiltrate alternating with necrobiotic degenerated collagen associated with foamy histiocytes and multimutated giant cells.

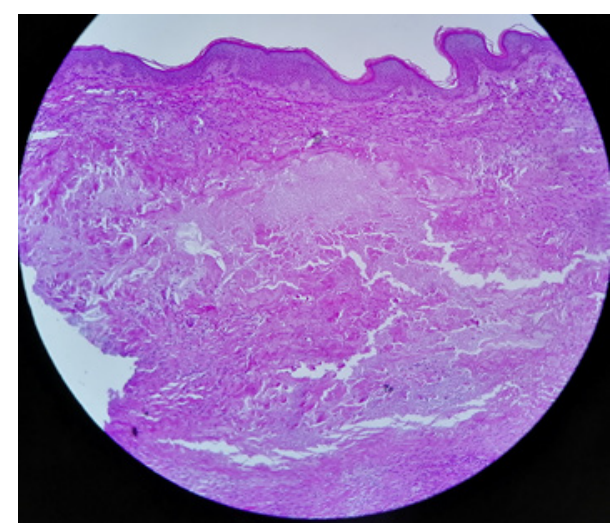

Fig. 4. Histopathological examination showed foamy histiocytes and multimutated giant cells.

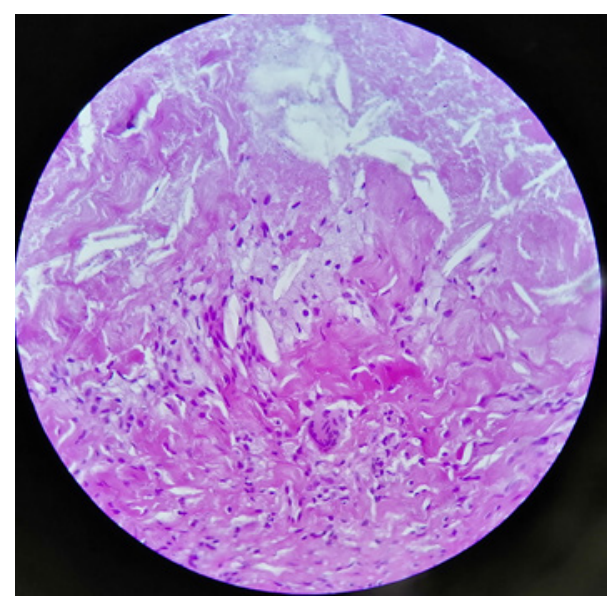

with foamy histiocytes and multimutated giant cells (shown in Fig. 3-4). Also, a few lymphocytes and plasma cells were seen. No significant mucin deposits using Alcian blue stain or cholesterol cleft were seen. Her fasting blood glucose level (14.2 mmol/L) and hemoglobin A1c (9.4\%) were elevated. Otherwise, her complete blood count, liver enzymes, urea, creatinine, thyroid function tests, serum and urine protein electrophoresis, and urinalysis were within normal ranges. She had a family history of type 1 diabetes mellitus. A combination treatment of superpotent topical corticosteroid (Clobetasol cream) under occlusion daily and monthly triamcinolone acetonide intradermal/subcutaneous injections (5-10 mg/mL) at the periphery of the lesion was administrated. The subsequent follow-up was arranged for 1 month for reevaluation and reinjection.

\section{Discussion/Conclusion}

NL is a chronic granulomatous idiopathic disorder, primarily affecting middle-aged women 20-30 years of age, typically in the pretibial region of both extremities with or without ulceration $[1,2]$. Pediatric NL cases were rarely reported, especially those that started before 15 years of age, and most had typical lesions in their lower extremities [4]. NL typically occurs in young to middle-aged adults, with a female: male ratio of $3: 1$. For diabetic patients, the average age at presentation is 25 years, whereas in nondiabetic patients, it is 46 years [5]. $\mathrm{NL}$ is characterized by yellow-brown, atrophic, telangiectatic plaques with an elevated violaceous 
rim, typically in the pretibial region. Less typical reported anatomic locations for NL include the upper extremities, face, and scalp [6]. Isolated cases of pediatric NL with non-leg involvement are extremely rare. Pestoni et al. [6] reviewed 11 cases of NL in children, all of which were found on the lower legs and forearms without isolated cases of non-leg involvement. Marcoval et al. [7] reviewed 35 cases of NL and found 2 non-leg cases ( 1 abdomen and 1 upper extremity), but none were in children. Özkur et al. [1] reported a nondiabetic 14-year-old girl diagnosed with NL in her back. Our patient had a solitary asymptomatic enlarging NL plaque over her arm that, to our knowledge, is the first in the literature. In addition, Pestoni et al. [6] found that only 4 of the 11 cases started before the age of 9 years, which suggests our patient had a very early onset of the disease.

A dermatoscopic examination can determine early and late NL lesions. Comma- or hairpin-shaped vessels and an irregular pattern of arborizing vessels are seen in early and more advanced lesions, respectively. Arborizing telangiectasias correspond to the vascular plexus present in the reticular dermis, and hairpin-like vessels correspond to papillary vessels that become more visible because of the inflammation and atrophic changes secondary to the degeneration of connective tissue. These findings could initially be explained by the visualization of the papillary vessels and, later, as atrophy progresses, to the increasing visibility of the vessels of the deep plexus. Also, whitish areas correspond to degenerated collagen and yellow-to-orange patches to granulomatous inflammation $[8,9]$.

The prevalence of NL in children with type 1 diabetes is unknown; the overall prevalence in all age groups is $0.3-1.2 \%[1,2]$. The association between NL and IDDM is unclear; it has been postulated that the microangiopathic vessel changes seen in diabetic patients could contribute to the development of collagen degeneration and subsequent dermal inflammation [5]. De Silva et al. found only one 15-year-old girl out of 1,557 diagnosed with NL on her shins, giving a prevalence of $0.06 \%$ [10]. No further prevalence-based studies have been conducted on NL in children.

The histopathological features are variable, depending to some extent on the presence or absence of coexistent diabetes mellitus and the biopsy site. The palisading granuloma with necrobiosis is more typical of the diabetes-related variant, whereas a granulomatous sarcoidal type of reaction is more often a feature of nondiabetes-related necrobiosis. A biopsy from the palpable inflammatory border can be performed, and a diffuse palisaded and interstitial granulomatous dermatitis that involves the entire dermis and extends into the subcutaneous fat septae is usually seen. In addition, "layered" tiers of granulomatous inflammation are composed of histiocytes surrounding horizontal tiers of degenerated collagen. A biopsy from areas of sclerosis can be done, and focal loss of elastic tissue may be seen. An associated superficial and deep perivascular infiltrate is predominantly lymphocytic but often contains plasma cells and occasionally eosinophils [5]. Cholesterol clefts are rare and may be prominent on rare occasions [11].

The most common complication of NL is ulceration; up to 35\% developed ulcerations after minor trauma. Rarely, squamous cell carcinoma (SCC) has been reported to develop within lesions of NL. However, it is unknown whether transformation into SCC results from long-standing NL or whether chronic ulceration predisposes these lesions to malignant transformation $[3,12]$.

No treatment for NL has been proven to be effective in large, double-blind, placebocontrolled studies. Spontaneous remission after an average of 8-12 years was observed in $17 \%$ of 171 patients [5]. In addition to avoidance of trauma and local care of ulcers, potent topical corticosteroids (including under occlusion) for early lesions and intralesional corticosteroids injected into the active borders of established lesions are usually the first-line treatment options. Based upon case series or prospective uncontrolled studies, several treatment options include systemic corticosteroid, antimalarials, niacinamide, mycophenolate mofetil, doxycycline,

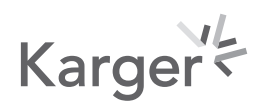


colchicine, methotrexate, thalidomide, TNF- $\alpha$ inhibitors, cyclosporine, PUVA, UVA1 phototherapy, fractional $\mathrm{CO}_{2}$ laser, or photodynamic therapy [13-16]. Long-term follow-up is essential to monitor for early signs of ulcerations or malignant transformation to SCC.

\section{Acknowledgment}

Mona Nosseir, MD, Pathology Consultant, is thanked for providing the histopathologic image.

\section{Statement of Ethics}

The paper is exempt from ethical committee approval since this is a single case report without identifying information about the patient. Written informed consent was obtained from the parent/legal guardian of the patient for publication of the details of their medical case and any accompanying images.

\section{Conflict of Interest Statement}

No conflict of interest.

\section{Funding Sources}

There are no funding sources for this case report.

\section{Data Availability Statement}

All data generated or analyzed during this study are included in this article. Further inquiries can be directed to the corresponding author.

\section{References}

1 Özkur E, Hasçiçek SÖ, Altunay İK. Atypical presentation of necrobiosis lipoidica in a pediatric patient. Pediatr Dermatol. 2019 Jan;36(1):e31-e33.

2 Ahmed I, Goldstein B. Diabetes mellitus. Clin Dermatol. 2006 Jul-Aug;24(4):237-46.

3 Erfurt-Berge C, Seitz AT, Rehse C, Wollina U, Schwede K, Renner R. Update on clinical and laboratory features in necrobiosis lipoidica: a retrospective multicentre study of 52 patients. Eur J Dermatol. 2012 Nov-Dec;22(6):770-5.

4 Jockenhöfer F, Kröger K, Klode J, Renner R, Erfurt-Berge C, Dissemond J. Cofactors and comorbidities of necrobiosis lipoidica: analysis of the German DRG data from 2012. J Dtsch Dermatol Ges. 2016 Mar;14(3):277-84.

5 Bolognia J, Schaffer J, Cerroni L. Chapter 93, non-infectious granulomatous. Dermatology. 4th ed. Elsevier; 2017. p. 1655-7.

6 Pestoni C, Ferreirós MM, de la Torre C, Toribio J. Two girls with necrobiosis lipoidica and type I diabetes mellitus with transfollicular elimination in one girl. Pediatr Dermatol. 2003 May-Jun;20(3):211-4.

7 Marcoval J, Gómez-Armayones S, Valentí-Medina F, Bonfill-Ortí M, Martínez-Molina L. Necrobiosis lipoidica: a descriptive study of 35 cases. Actas Dermosifiliogr. 2015 Jun;106(5):402-7.

8 Bakos RM, Cartell A, Bakos L. Dermatoscopy of early-onset necrobiosis lipoidica. J Am Acad Dermatol. 2012 Apr;66(4):e143-4.

9 Conde-Montero E, Avilés-Izquierdo JA, Mendoza-Cembranos MD, Parra-Blanco V. Dermoscopy of necrobiosis lipoidica. Actas Dermosifiliogr. 2013 Jul-Aug;104(6):534-7. 
10 De Silva BD, Schofield OM, Walker JD. The prevalence of necrobiosis lipoidica diabeticorum in children with type 1 diabetes. Br J Dermatol. 2000 Jan;142(1):201.

11 De la Torre C, Losada A, Cruces MJ. Necrobiosis lipoidica: a case with prominent cholesterol clefting and transepithelial elimination. Am J Dermatopathol. 1999 Dec;21(6):575-7.

12 Lim C, Tschuchnigg M, Lim J. Squamous cell carcinoma arising in an area of long-standing necrobiosis lipoidica. J Cutan Pathol. 2006 Aug;33(8):581-3.

13 Durupt F, Dalle S, Debarbieux S, Balme B, Ronger S, Thomas L. Successful treatment of necrobiosis lipoidica with antimalarial agents. Arch Dermatol. 2008 Jan;144(1):118-9.

14 Reinhard G, Lohmann F, Uerlich M, Bauer R, Bieber T. Successful treatment of ulcerated necrobiosis lipoidica with mycophenolate mofetil. Acta Derm Venereol. 2000 Jul-Aug;80(4):312-3.

15 Suárez-Amor 0, Pérez-Bustillo A, Ruiz-González I, Rodríguez-Prieto MA. Necrobiosis lipoidica therapy with biologicals: an ulcerated case responding to etanercept and a review of the literature. Dermatology. 2010; 221(2):117-21.

16 Beattie PE, Dawe RS, Ibbotson SH, Ferguson J. UVA1 phototherapy for treatment of necrobiosis lipoidica. Clin Exp Dermatol. 2006 Mar;31(2):235-8. 